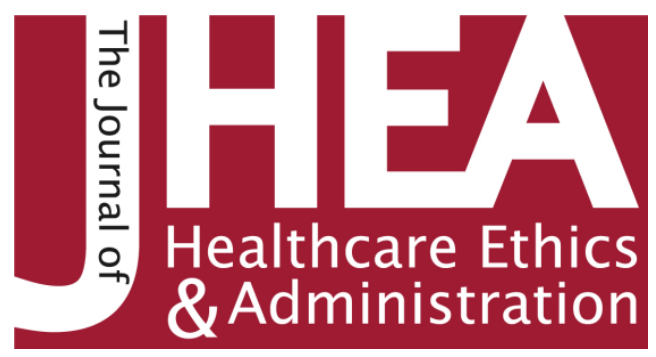

COMMENTARY

\title{
The Missing Student at Graduation
}

LETTY PIPER, ED.D., MSN, RN

piper@lasalle.edu

School of Nursing and Health Sciences, La Salle University, Philadelphia, U.S.A.

*Address correspondence to: Letty Piper, Ed.D., MSN, RN, Nursing Workforce, Strategies for Success Program, School of Nursing and Health Sciences, La Salle University, 1900 West Olney Avenue, Philadelphia, PA 19141. E-mail: piper@lasalle.edu

Find this and more works at www.jheaonline.org

This work is brought to you for free and open access by the Institute of Clinical Bioethics (ICB) at Saint Joseph's University, Philadelphia, PA, U.S.A. It has been accepted for inclusion in The Journal of Healthcare Ethics \& Administration by editorial board and an authorized administrator of the JHEA. For more information, please contact support@jheaonline.org 


\title{
COMMENTARY
}

\section{The Missing Student at Graduation}

\author{
LETTY PIPER, ED.D., MSN, RN \\ piper@lasalle.edu \\ School of Nursing and Health Sciences, La Salle University, Philadelphia, U.S.A.
}

Keywords: multiculturalism, Asian culture, nursing

It was a glorious May morning. The parking lot was filling with cars carrying happy families. This was the day so many had waited four years for. Graduation Day had arrived. All was joyous for a faculty that could see the culmination of their work. About an hour after the ceremony, a family with South Asian roots, appeared at the Dean's office asking why their daughter wasn't in the graduation.

What could we say, how could we deal with this? The student in question had failed out of the program a semester earlier. Was it possible that the parents were not aware? Were we the ones to tell them? How could this be?

As the number of college age students has declined and tuition costs risen, universities are having more difficulty keeping enrollment levels up. This need for raw material has driven some universities to lower their admission standards to increase their volume. Although admissions are increasing, so too are dropouts. This commentary will explore the ethical issues that arise in such an environment.

Beneficence and Social Justice are served by the expansion of opportunity for admitted students. Students and their families are pleased with their opportunity and willingly incur debt to further the individual's future. However, we the academic community, know that these students come to us with a higher likelihood of failure. The odds of reaping the benefits of a degree are significantly slimmer for these students. What is our obligation to the student and their family?

Do we have an obligation to tell the student that research and experience tells us that they are highly likely to drop or fail out of the University. They are likely to carry significant debt without the wherewithal to engage in repayment. Has our statement of admission conveyed that the student is qualified to perform adequately in their desired program? Are we sharing what they need to know to make such a large financial decision?

What complicated the above example came the next day. The parents called to tell us that their daughter had committed suicide. In her note she explained that she was unable to face the disappointment she would impose on her parents. She left the house everyday to make them believe she was going to school, but when graduation day came she could no longer keep up the ruse.

This situation initiated a significant amount of self exploration. Were we giving students adequate support? Was our support system culturally sensitive? Did we understand the emotional burden that students who are children of Asian immigrants carry? Had we somehow committed educational maleficence? What was our obligation? Although no snowflake individually causes an avalanche, no one professor had caused this human tragedy. What could we as a group do to prevent a repeat case. We felt it was our ethical duty to consider our actions.

As the director of a Student Tutoring Center, I have seen many students come to the center after a test or class failure. Many of them are as concerned about what to do to improve their grades as they are concerned about how to tell their families. Recently we have begun counselling these students on the family issues along with the academic issues. We often use role play to prepare them for their delivery of the message. But our understanding of the cultural pressures that students face is limited. Our faculty is 
only marginally diverse and we have no faculty members with an Asian background. As our students have become more diverse, we have not kept pace.

$\mathrm{Xu}$, Davidhizar \& Joyce (2005) examine the difficulties faced by faculty when dealing with students from an Asian culture. They discuss Asian cultures' respect for authority, which may reduce the students' willingness to ask questions or to challenge professors. The need to save face is also an important aspect of the Asian culture which impedes the students' willingness to participate in discussion. The fear of making an error or speaking incorrectly can lead to a lack of class participation or in class questions.

Fear of loss of face extends to family loss of face. Failure is not only seen as an individual crisis but a family crisis. "American faculty need to understand the intense intra-personal tension and agony frequently have been building up behind this seeming quietness and silence" of the student. ${ }^{1}$

The healthcare industry is presently attempting to increase the cultural diversity of it's workforce to match the diversity of our patient populations. The belief is that unless the social determinants of the caregiver matches the social determinants of the client, there will be a less than satisfactory outcome. This movement will require a culturally diverse faculty and programs to educate culturally diverse faculty candidates, and a culturally diverse student body. Social justice calls for the educator or care provider to be culturally aware and culturally sensitive. The awareness and sensitivity lends credibility and authority to the outreach.

Until we can increase the cultural diversity of our faculty, we will be required to have our faculties more culturally aware and more sensitive to the needs and cultural demands of our diverse students. Faculty development programs designed to prepare faculty and courses for the diverse needs of students, will have to be developed and implemented. Although we as faculty are qualified to present our areas of expertise, we are not necessarily prepared to work with or support students from diverse cultures and backgrounds.

\section{REFERENCES}

Xu, Y., Davidhizar, R., and Joyce, N. "What if Your Nursing Student is from an Asian Culture?" Journal of Cultural Diversity (2005) 12(1).

${ }^{1}$ Y. Xu, R. Davidhizar, and N. Joyce, "What if Your Nursing Student is from an Asian Culture?” Journal of Cultural Diversity (2005) 12(1): 511 